\title{
An Approach to Orbital Complications in Rhinosinusitis
}

\author{
Serkan Çayır ${ }^{1}$, Serkan Kayabașı ${ }^{1}$ \\ 1 Department of Ear Nose and Throat and Head and Neck Surgery, Aksaray \\ University Faculty of Medicine, Aksaray, Turkey \\ Serkan Çayır, ORCID: 0000-0003-4663-6293 \\ Serkan Kayabaşı, ORCID: 0000-0002-5292-5940
}

\begin{abstract}
Objective: Whilst orbital complications arising from acute rhinosinusitis are infrequent in contemporary practice, the spread of infection orbitally or intracranially can result in severe complications and a high mortality. This study aims to review cases of orbital complications arising from rhinosinusitis in the light of the published literature on the topic.

Methods: Eight cases of individuals presenting to a particular clinic with the development of orbital complications following sinusitis within the previous four years were included in the study. The characteristic features of these cases in terms of diagnosis, treatment and follow-up were investigated.
\end{abstract}

Results: The mean age of all cases was 29.5 years. In three cases, orbital abscess, and in five cases, preseptal cellulitis, were observed as complications. Both surgical and medical treatment was administered in three cases, while medical treatment alone was used for five cases.

Conclusion: The region where the complications of rhinosinusitis are most commonly observed is the orbit, due to its proximity to the paranasal sinuses, especially the ethmoid cells. Where limitation of eye movements, proptosis, and a decrease in vision exists alongside an orbital abscess which itself has developed as a complication of sinusitis, surgical treatment is the most important option to consider to prevent complications.

Keywords: Orbit, sinusitis, orbital cellulitis, abscess.

\section{Introduction}

Orbital infections can result from multiple different causes such as initial sinusitis, trauma, dental abscess, peribulbar operations, closed fractures, dacryocystitis, immunosuppression, and so forth. ${ }^{[1]}$ Nowadays, although antibiotics are frequently used in the treatment of sinusitis, complications may still occur. ${ }^{[2]}$ There are a number of complications that can occur if sinusitis leads to the spread of infection intracranially or intraorbitally. Orbital complications are rarely observed, but occur more frequently in children than adults. The orbital septum acts as a barrier preventing the spread of infection from the preseptal region to the orbital region. Infection in the sinuses can spread via lymphatic, venous, or perineural routes. ${ }^{[3]}$ Since the ethmoid cells are in close proximity to the orbit, this is the region most commonly affected when complications do occur. Preseptal cellulitis, orbital cellulitis, subperiosteal abscess, orbital abscess, and cavernous sinus thrombosis are types of orbital complication found in sinusitis. ${ }^{[2,3]}$ As infection takes hold, limitation of movement in the bulbus oculi, diplopia, chemosis, proptosis, a decrease in the pupillary reflex, a decrease in visual acuity or even permanent vision loss may be observed..$^{[1-3]}$ 
The objective of this study was to review those cases presenting to our clinic over the previous four years where orbital complications had developed due to rhinosinusitis, and to compare them with the current state of knowledge, as reflected in the literature on this topic.

\section{Materials and Methods}

The study was undertaken in accordance with the principles contained in the Declaration of Helsinki, and involved a retrospective file review. In this study, eight patients were reviewed retrospectively. These individuals had been hospitalised, diagnosed or had undergone treatment and/or follow-up in our clinic between January 2014 and November 2018 because of orbital complications from rhinosinusitis. Details of the history were extracted from the patients' case records. The cases had been evaluated by routine otorhinolaryngological examination and nasal endoscopy. In the endoscopic examination, Karl-Storz 4mm rigid $0^{\circ}, 30^{\circ}$, and $70^{\circ}$ Hopkins lens rigid endoscopes (Storz, St Louis, MI, USA) had been used. In the detailed eye examination performed by an ophthalmologist, the pathological appearance of the eyelids and surrounding tissues (particularly the presence of oedema or hyperaemia) were evaluated on the basis of eye movements, visual field examination, and functional integrity. Radiological diagnosis and follow-up of the patients was achieved by taking $4 \mathrm{~mm}$ coronal and axial sections in the axial and coronal planes so as to include the paranasal sinus and orbital sections, by means of a Toshiba Aquilion 640-slice CT (Computed tomography) (Toshiba Medical Systems, Otawara, Japan, 2012). The patients' ear, nose, and throat disease examination results, demographic data, radiological imaging results, details of medical and surgical treatment, and follow-up results were analysed.

In all cases, intravenous ceftriaxone (adult dose 1-2 g/ day, paediatric dose $50-75 \mathrm{mg} / \mathrm{kg} /$ day) + ornidazole $2 \times 500$ $\mathrm{mg}$ (adult dose $2 \times 500 \mathrm{mg} /$ day, $25 \mathrm{mg} / \mathrm{kg}$ in children, divided into 2 doses per day) + saline irrigation + local decongestant treatment were started as medical treatment. Surgical intervention was undertaken in cases featuring limitation of eye movements, a decrease in vision or no response to medical treatment within a 24 hour period.

\section{Results}

A total of 8 patients, five males $(63 \%)$ and three females (37\%), with a mean age of 29.5 (range: $11-70$ ) years, were included in the study. The diagnosis in five cases was preseptal cellulitis $(63 \%)$ (Figure 1). Three patients were diagnosed with an orbital abscess (37\%) (Figure 2). The main complaints in the cases with orbital complications were fever, nasal congestion, postnasal drip, headache, swelling of the eyes, and decreased visual acuity. The frequency of the various symptoms and signs of orbital complications is presented in Table 1 . The mean hospital stay was nine days. Endoscopic sinus surgery (ESC) + orbital decompression + external abscess drainage were performed in two patients, and ESC + orbital decompression were performed in one patient, while medical treatment alone was undertaken in five patients. After treatment, no functional or aesthetic problems were encountered in the patients. The clinical characteristics, complications, and details of treatment of the patients are presented in Table 2 .
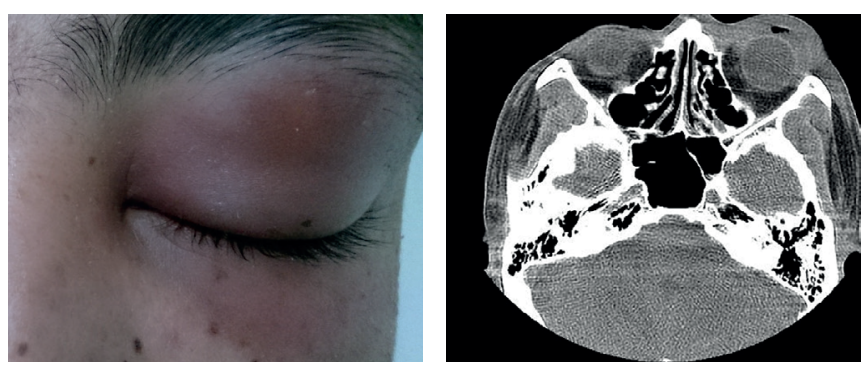

Figure 1. Left preseptal cellulitis
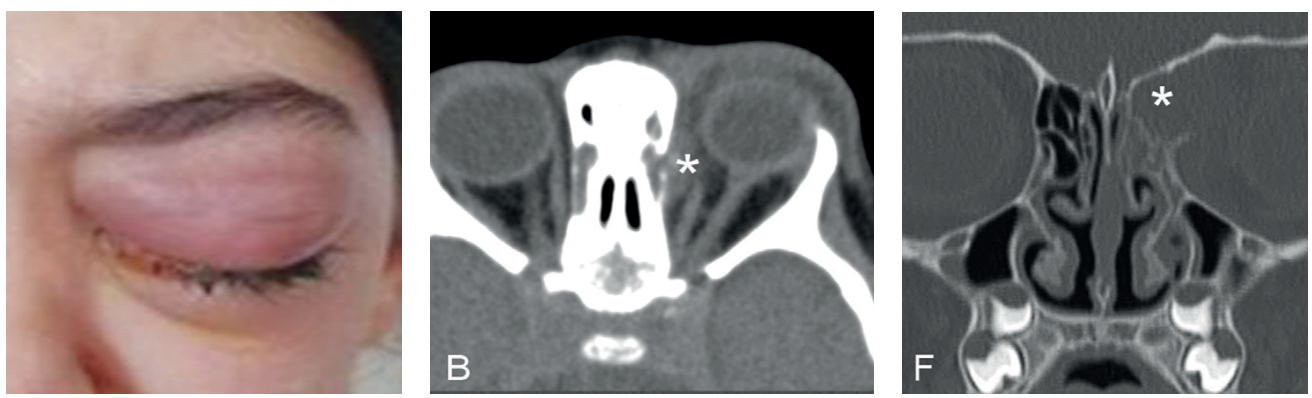

Figure 2. Left orbita abscess (white star) 
Table 1. Symptoms and signs of orbital complications.

$\begin{array}{lll}\text { Sign } & \mathbf{n} & (\mathbf{\%}) \\ \text { Nasal congestion/discharge } & 6 & (75 \%) \\ \text { Fever } & 4 & (50 \%) \\ \text { Headache } & 5 & (62 \%) \\ \text { Eyelid Edema } & 8 & (100 \%) \\ \text { Eye pain } & 5 & (62 \%) \\ \text { Blurred vision } & 2 & (25 \%) \\ \text { Loss of vision } & 2 & (25 \%)\end{array}$

\section{Discussion}

The frequency of orbital complications observed in acute rhinosinusitis significantly decreased following endoscopic nasal examination, radiological imaging, and appropriate antibiotic therapy ${ }^{[4]}$ Complications are frequently observed in patients who do not receive adequate treatment for acute suppurative sinusitis or who suffer acute exacerbations in chronic sinusitis. These complications are grouped under three main headings: orbital, intracranial and osseous. The most common are orbital complications. Haemophilus influenzae, Streptococcus pneumoniae and Staphylococcus aureus are the principal pathogens in orbital complications. In acute rhinosinusitis infections, the route of spread to the surrounding tissues may be direct, venous, lymphatic or perineural. Direct regional spread occurs via osteitis in compact bones and osteomyelitis in diploic bones. ${ }^{[4,5]}$ When the orbital tissues become infected, clinical signs appear over a broad spectrum, ranging from mild to severe. The most important factor determining the presentation of symptoms and signs in infection is which anatomical region of the orbit is involved, and the severity of the involvement. Orbital complications are associated with ethmoid, maxillary, frontal and, rarely, sphenoid sinusitis, with ethmoid sinusitis the most common and sphenoid sinusitis the least. Since these complications can result in serious morbidity and high mortality, it is critical to diagnose and treat them quickly.

Paranasal sinus tomography (PNS-CT) is a radiological imaging method used both to confirm the diagnosis of acute rhinosinusitis and to plan the surgical treatment of the complications of paranasal sinusitis or rhinosinusitis. PNS-CT has a high degree of effectiveness and is frequently a preferred modality in the evaluation of paranasal sinus infections and complications. PNS-CT offers benefit at each stage in the diagnosis and treatment of complica-

Table 2: Clinical features and treatment modalities of the patients.

\begin{tabular}{llll}
\hline Age-Gender & Complication & Eye signs & Treatment \\
$14-\mathrm{M}$ & Orbital abscess & $\begin{array}{l}\text { Reduced vision }+ \\
\text { limited movement }\end{array}$ & ESC + orbital decompression + external drainage \\
$70-\mathrm{F}$ & Preseptal cellulitis & Normal & Medical \\
$19-\mathrm{F}$ & Preseptal cellulitis & Normal & Medical \\
$11-\mathrm{M}$ & Orbital abscess & Reduced vision + & ESC + orbital decompression + external drainage \\
& Preseptal cellulitis & limited movement & \\
$66-\mathrm{M}$ & Preseptal cellulitis & Normal & Medical \\
28-F & Orbital abscess & Normal & Medical \\
$15-\mathrm{M}$ & Preseptal cellulitis & Normal vision, limit- & ESC + orbital decompression \\
$13-\mathrm{M}$ & ed movement & Normal & Medical \\
\hline
\end{tabular}


tions, including abscess formation. MRI imaging is the modality of choice for the evaluation of soft tissues in cases of cavernous sinus thrombosis and cerebral abscess. MRI may be preferable to CT for paediatric patients who will be monitored at close intervals and thus are at risk from cumulative radiation damage. ${ }^{[6]}$

Since the retina and optic nerve can only tolerate ischaemia for a very short period, typically $1-2$ hours, vision and eye movements should be evaluated as soon as possible. ${ }^{[7]}$ Patients with orbital complications require hospitalisation, and the antibiotic selected for treatment needs to be effective against streptococci, staphylococci, aerobes and anaerobes, which may be responsible for sinusitis. Good results have been reported in the literature with 3rd-generation cephalosporins, clindamycin and metronidazole in combination, and sulbactam-ampicillin, and researchers stress the need for intravenous antibiotic therapy to last for 7-14 days. ${ }^{[8,9]}$

In the literature, there are different approaches described to achieve surgical drainage in cases where a subperiosteal or orbital abscess develops. Garcia et al ${ }^{[10]}$ monitored abscesses that were small, medial and not secondary to a tooth infection, in patients under nine years of age on medical therapy. They reported obtaining a response to medical treatment in $93 \%$ of cases. Yang et al ${ }^{[11]}$ argued that, since the ostium is wider and the sinus receives superior ventilation at earlier ages, the proliferation of anaerobic flora is prevented, and thus spontaneous drainage is easier. Siedek et al ${ }^{[12]}$ report draining surgically $90 \%$ of cases where abscesses occurred.

Patients in stages 1 and 2 of Chandler's classification ${ }^{[5]}$ are often treated with a conservative approach, whilst patients in stages 4 and 5 are usually treated surgically. Treatment methods in stage 3 patients are controversial. ${ }^{[13]}$ Teinzer et al ${ }^{[14]}$ stated that in stage 3, 4 and 5 patients, urgent surgery should be performed within 24 hours. There are currently some authors who suggest that medical treatment can still be used in patients with a subperiosteal abscess in whom vision and intraocular pressure are normal, proptosis is smaller than $5 \mathrm{~mm}$, eye movement is not limited, and abscess width is smaller than $4 \mathrm{~mm} \cdot{ }^{[14,15]}$ In another evaluation, it was reported that the best treatment modality was surgery in cases where vision is impaired and eye movements limited, proptosis is greater than or equal to $5 \mathrm{~mm}$, intraocular pressure is greater than $20 \mathrm{mmHg}$, and the size of the abscess exceeds $1 \mathrm{~cm} \cdot{ }^{[16]}$ While in the case of a medially located subperiosteal abscess, the endoscop- ic approach is widely used in surgical treatment, external drainage is needed if the abscess is superiorly located. ${ }^{[17,18]}$ Currently, some authors suggest the combined approach (external drainage + endoscopic approach) in large-sized abscesses with medial, superior or medial/superior co-location. ${ }^{[19]}$ Additionally, some authors have stressed the necessity of surgical drainage in subperiosteal orbital abscesses greater than $500 \mathrm{~mm}^{3}$ in volume or $1 \mathrm{~cm}$ in diameter. ${ }^{[20]}$

In this study, patients with acute rhinosinusitis, who were suspected, on the basis of a suitable history, physical examination and detailed endoscopy, of having orbital complications, were hospitalised, and intravenous antibiotherapy (ceftriaxone+ornidazole) + local decongestant + saline irrigation therapy were initiated. A specialist ophthalmic consultation was sought in order to evaluate vision in all patients, and PNS-CT was requested. Surgical treatment was undertaken within 24 hours in cases where an orbital abscess was accompanied by proptosis, ophthalmoplegia, and loss of vision. Consistently with the recommendations in the literature, the combined surgical approach was applied in 2 patients with a superiorly located abscess, and ESC + drainage were performed in 1 patient with a medially located abscess. Kim et al ${ }^{[2]}$ have reported that navigation-aided endoscopic surgery in a superiorly located orbital abscess is safe. Roithmann et al ${ }^{[22]}$ report the successful application of endoscopic drainage to a patient with a superiorly located abscess. Another author states that, in the presence of large collections of pus, medical treatment is usually insufficient as sole therapy, and should be combined with surgical treatment in older children and in cases featuring visual impairment. ${ }^{[23]}$ While the conservative approach is strongly recommended in the literature for abscesses which are medially located and smaller than $0.5 \mathrm{~cm}^{3}$, Gavriel et al ${ }^{[23]}$ argue that the conservative treatment approach is also safe for superiorly located abscesses smaller than $0.5 \mathrm{~cm}^{3}$.

\section{Conclusion}

In patients diagnosed with sinusitis with swelling and redness of the eyelids, a detailed ophthalmologic examination is essential, including globe movements and visual acuity. In cases where there is limitation in eye movements and a decrease in visual acuity, surgical drainage should be performed as an emergency. Conservative treatment can be applied in small-sized subperiosteal abscesses when vision is normal and there is no preseptal cellulitis, orbital cellulitis, or limitation of eye movements. 
Ethics Committee Approval: The local ethics committee approved the study with the project number of E-771.

Informed Consent: Informed consent was not received due to the retrospective nature of the study.

Author Contributions: Designing the study - S.Ç.; Collecting the data - S.K.; Analyzing the data - S.Ç., S.K.; Writing the

\section{References}

1. Pereira FJ, Velasco e Cruz AAV, Anselmo-Lima WT, Elias Júnior J. Computed tomographic patterns of orbital cellulitis due to sinusitis. Arq Bras Oftalmol 2006;69:513-8.

2. Szyfter W, Bartochowska A, Borucki $Ł$, Maciejewski A, Kruk-Zagajewska Simultaneous treatment of intracranial complications of paranasal sinusitis. Eur Arch Otorhinolaryngol 2018;275:1165-73.

3. Watkins LM, Pasternack MS, Banks M, Kousoubris P, Rubin PA. Bilateral cavernous sinus thromboses and intraorbital abscesses secondary to Streptococcus milleri. Ophthalmology 2003;110:569-74.

4. Rosenfeld RM, Piccirillo JF, Chandrasekhar SS, et al. Clinical practice guideline (update): adult sinusitis. Otolaryngol Head Neck Surg 2015;152:1-39.

5. Chandler JR, Langenbrunner DJ, Stevens ER. The pathogenesis of orbital complications in acute sinusitis. Laryngoscope 1970;80:1414-28.

6. Patel NA, Garber D, Hu S, Kamat A. Systematic review and case report: Intracranial complications of pediatric sinusitis. Int J Pediatr Otorhinolaryngol 2016;86:200-12.

7. Segal N, Nissani R, Kordeluk S, et al. Orbital complications associated with paranasal sinus infections - A 10-year experience in Israel. Int J Pediatr Otorhinolaryngol 2016;86:60-2.

8. Teinzer F, Stammberger H, Tomazic PV. Transnasal endoscopic treatment of orbital complications of acute sinusitis: the Graz concept. Ann Otol Rhinol Laryngol 2015;124:368-73.

9. Atfeh MS, Singh K, Khalil HS. Orbital infections: a complete cycle 7year audit and a management guideline. Eur Arch Otorhinolaryngol 2018;275:2079-88.

10. Garcia GH, Harris GJ. Criteria for nonsurgical management of subperiosteal abscess of the orbit: analysis of outcomes 1988-1998. Ophthalmology 2000;107:1454-6.

11. Yang M, Quah BL, Seah LL, Looi A. Orbital cellulitis in children-medical treatment versus surgical management. Orbit 2009;28:124-36.

12. Siedek V, Kremer A, Betz CS, Tschiesner U, Berghaus A, Leunig A. Management of orbital complications due to rhinosinusitis. Eur Arch Otorhinolaryngol 2010;267:1881-6. manuscript - S.Ç.; Confirming the accuracy of the data and the analyses - S.C.., S.K.

Conflict of Interest: The authors have no conflicts of interest to declare.

Financial Disclosure: The authors declared that this study has received no financial support.
13. Gavriel H, Jabrin B, Eviatar E. Management of superior subperiosteal orbital abscess. Eur Arch Otorhinolaryngol 2016;273:145-50.

14. Jabarin B, Eviatar E, Israel O, Marom T, Gavriel H. Indicators for imaging in periorbital cellulitis secondary to rhinosinusitis. Eur Arch Otorhinolaryngol 2018;275:943-8.

15. Oxford LE, McClay J. Medical and surgical management of subperiosteal orbital abscess secondary to acute sinusitis in children. Int J Pediatr Otorhinolaryngol 2006;70:1853-61.

16. Bedwell JR, Choi SS. Medical versus surgical management of pediatric orbital subperiosteal abscesses. Laryngoscope 2013;123:2337-8.

17. Sciarretta V, Demattè M, Farneti $P$, et al. Management of orbital cellulitis and subperiosteal orbital abscess in pediatric patients: A ten-year review. Int J Pediatr Otorhinolaryngol 2017;96:72-6.

18. Ketenci I, Unlü Y, Vural A, Doğan H, Sahin MI, Tuncer E. Approaches to subperiosteal orbital abscesses. Eur Arch Otorhinolaryngol 2013;270:1317-27.

19. Erickson BP, Lee WW. Orbital Cellulitis and Subperiosteal Abscess: A 5-year Outcomes Analysis. Orbit 2015;34:115-20.

20. Tabarino F, Elmaleh-Bergès M, Quesnel S, Lorrot M, Van Den Abbeele T, Teissier N. Subperiosteal orbital abscess: volumetric criteria for surgical drainage. Int J Pediatr Otorhinolaryngol 2015;79:131-5.

21. Kim JH, Kim SH, Song CI, Kang JW. Image-guided nasal endoscopic drainage of an orbital superior subperiosteal abscess. Br J Oral Maxillofac Surg 2016;54:26-8.

22. Roithmann R, Uren B, Pater J, Wormald PJ. Endoscopic drainage of a superiorly based subperiosteal orbital abscess. Laryngoscope 2008;118:162-4.

23. Tunkel DE. Drainage of subperiosteal orbital abscess in children. In: Kennedy D, editor. Master Techniques in Otolaryngology Head and Neck Surgery: Rhinology. Alphen aan den Rijn, Wolters Kluwer Health Adis; 2015. p. 287-97.

24. Gavriel H, Yeheskeli E, Aviram E, Yehoshua L, Eviatar E. Dimension of subperiosteal orbital abscess as an indication for surgical management in children. Otolaryngol Head Neck Surg 2011;145:823-7.

This is an open access article distributed under the terms of the Creative Commons Attribution-NonCommercial-NoDerivs 3.0 Unported (CC BY- NC-ND3.0) Licence (http://creativecommons.org/licenses/by-nc-nd/3.0/) which permits unrestricted noncommercial use, distribution, and reproduc- tion in any medium, provided the original work is properly cited.

Please cite this article as: Çayır S, Kayabaşı S. An Approach to Orbital Complications in Rhinosinusitis. ENT Updates 2019;9(3): 180-184 